\section{Value for money}

Sir - Scientists are currently judged by the number and quality of their publications ${ }^{1}$. Using such criteria, Robert May's "Review of world science" ${ }^{2}$ finds that the economically developed nations fare well, whether the results are expressed in terms of citations per person or a relative citation index. In today's economic climate, he suggests that the United Kingdom obtains the "best value for money" at 168.2

citations per million pounds sterling. Such a figure implies that each publication costs $\mathfrak{E}, 945$ or US $\$ 9,530$. May further suggests that better value for money is associated with university institutions.

Several of my South African colleagues in the life sciences at university institutions have provided me with their average costs per publication. These range from $\$ 500$ to $\$ 2,400$. The average is $\$ 2,000$. This is not a very realistic figure because chemicals are purchased from outside South Africa and are subject to $10 \%$ import duty and $14 \%$ value-added tax. So the real cost for each publication is $\$ 1,520$.

Sceptical of the quality of these publications? These colleagues are publishing in journals with impact factors from 1.7 to 5.2 . This suggests that we are producing 6 papers for each produced in the United Kingdom, and 7 for each produced in the United States. If we include the cost of the manpower involved, we arrive at 24 and 28 publications respectively for the same investment - South African lecturers receive $\$ 14,000$ a year (less than a quarter of salaries on offer in the United States as judged by classified advertisements). I should like to suggest that funding agencies in Europe and the United States should invest in South African science in our universities for real "value for money".

\section{J. P. Dean Goldring}

Department of Biochemistry,

University of the Witwatersrand,

1 Jan Smuts Avenue,

Johannesburg, South Africa

e-mail:089goldr@cosmos.wits.ac.za

1. Lewison, G., Anderson, J. \& Jack, J. Nature 377, 671 (1995).

2. May, R. Science 275, 793-796 (1997).

\section{History of parity} violation experiment

Sir - The Commentary article "Parity and chivalry in nuclear physics" refers to the two first publications demonstrating the nonconservation of parity in the weak interactions $\mathrm{s}^{2,3}$. The article is summarized by the subhead "Forty years ago, the world of physics was stunned by the discovery that nuclear beta-decay does not respect symmetry between left and right. But the credit for this conclusion has not been properly attributed." The purpose of the Commentary was "...to state for the record that the NBS [National Bureau of

Standards] parity violation experiment was a collaborative team effort in which nuclear physicists and cryophysicists pooled their knowledge and expertise to carry out an experiment proposed by Lee and Yang, thus confirming their hypothesis that parity is not conserved in $\beta$-decay".

We have always regarded this epochal experiment as a team effort. When we wrote in 1957, "[w] e are also indebted to Professor C. S. Wu for reports of her preliminary results in the Co- 60 experiment which played a crucial part in the Columbia discussions immediately preceding this experiment", we did not intend to apportion credit among the authors of the Letter reporting the Co-60 results. Our own experiment,

"Observations of the failure of conservation of parity and charge conjugation in meson decays: the magnetic moment of the free muon", was spurred by Wu's Friday-lunch report of the status of the Co-60 experiment and was performed that Friday night, 4 January 1957, to

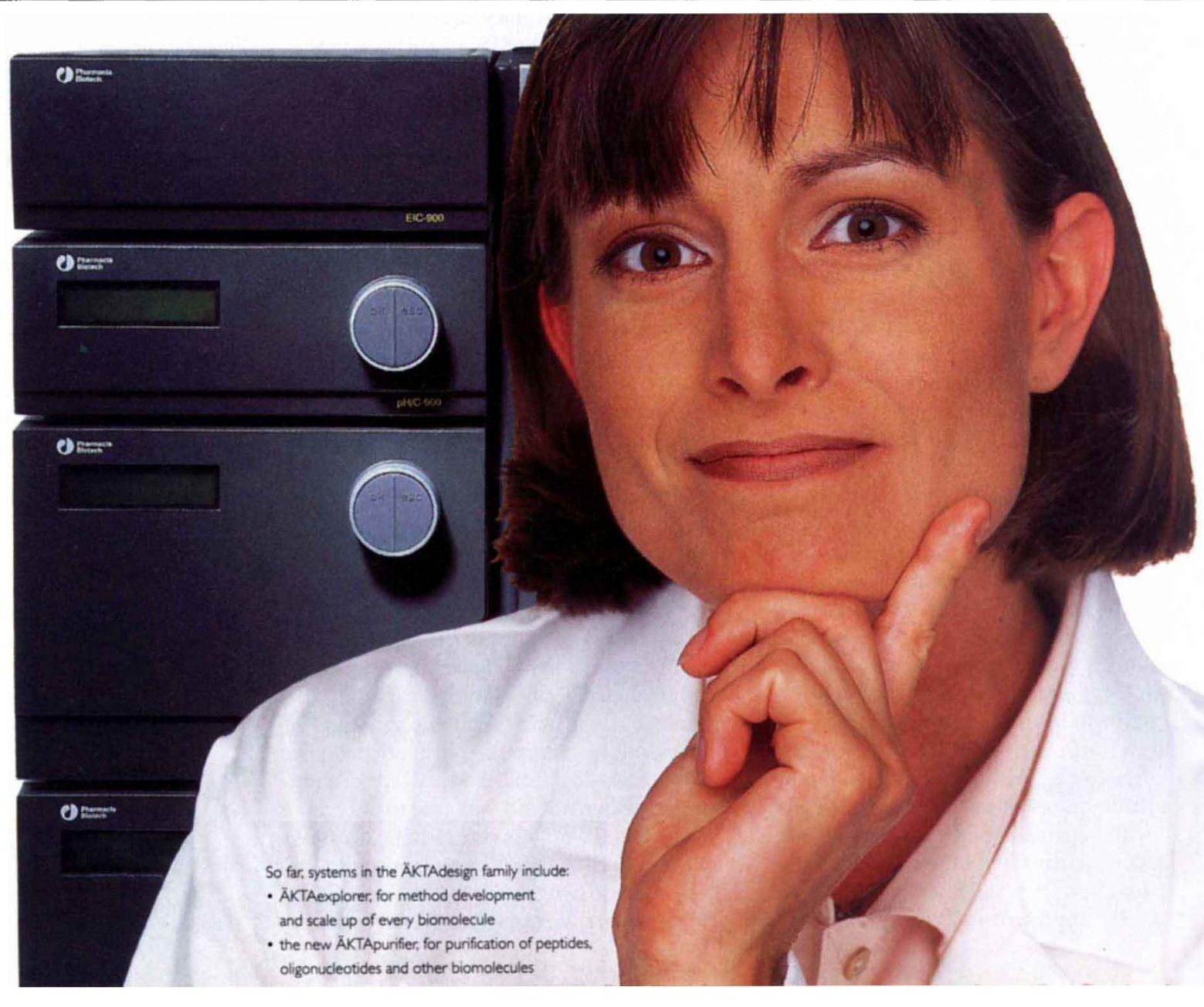

